\title{
Skrining Fitokimia, Uji Toksisitas dan Uji Peredaman Radikal DPPH Ekstrak Daun Gelinggang (Cassia alata L.)
}

\section{[Phytochemical Screening, Toxicity Test and DPPH Radical Scavenging Test of Cassia alata L. (Gelinggang) Leaves Extract]}

\author{
Izkia Mawaddah $^{1}$, Erwin $^{1 *}$, Chairul Saleh ${ }^{1}$ \\ ${ }^{1} J u r u s a n$ Kimia Fakultas Matematika dan Ilmu Pengetahuan Alam Jl. Barong Tongkok Kampus Gunung Kelua \\ UNMUL Samarida Kalimantan Timur, 75123 \\ ${ }^{\star}$ Coresponding author: winulica@yahoo.co.id
}

\begin{abstract}
Cassia alata L. (Gelinggang) one of the plants known as medicinal plants, especially for the treatment of skin diseases. The purpose of this study was to determine the type of secondary metabolites using phytochemical tests, toxicity with the BSLT method and antioxidant properties against DPPH radicals from the extract of the Gelinggang leaves. The results of the study showed extracts of Gelinggang leaves containing alkaloids, triterpenoids, steroids, and quinones. Based on the results of toxicity and antioxidant tests showed that Gelinggang leaves extract was very toxic to Artemia salina shrimp and it was a strong antioxidant against DPPH radicals with $\mathrm{LC}_{50}$ and $\mathrm{IC}_{50}$ were $28.84 \mathrm{ppm}$ and $73.57 \mathrm{ppm}$, respectively.
\end{abstract}

Keywords: Gelinggang, Cassia alata L., toxicity, antioxidants, DPPH

ABSTRAK. Cassia alata L. (Gelinggang) merupakan salah satu tumbuhan yang dikenal sebagai tumbuhan yang berkhasisat obat terutama untuk mengobati penyakit gatal-gatal. Tujuan penelitian ini adalah untuk mengetahui kandungan metabolit skunder dengan menggunakan uji fitokimia, toksisitas dengan metode BSLT dan sifat antioksidan terhadap radikal DPPH dari ekstrak kasar daun Gelinggang. Hasil penelitian menunjukkan ekstrak daun gelinggang mengandung alkaloid, triterpenoid, steroid, dan kuinon. Berdasarkan hasil uji toksisitas dan antioksidan menunjukkan bahwa ekstrak kasar daun gelinggang sangat toksit terhadap udang Artemia salina dan bersifat antioksidan kuat terhadap radikal $\mathrm{DPPH}$ dengan $\mathrm{LC}_{50}$ dan $\mathrm{IC}_{50}$ secara berturut-turut adalah $28,84 \mathrm{ppm}$ dan 73,57 ppm.

Kata kunci : Gelinggang, Cassia alata L., toksisitas, antioksidan, DPPH

Riwayat artikel: Diterima 30 Maret 2020, Disetujui 12 April 2020

Cara sitasi: Mawaddah, I., Erwin., Saleh, C. (2020). Skrining Fitokimia, Uji Toksisitas dan Uji Peredaman Radikal DPPH Ekstrak Daun Gelinggang (Cassia alata L). KOVALEN: Jurnal Riset Kimia, 6(1): 61-66.

DOI: https://doi.org/10.22487/kovalen.2020.v6.i1.15045

\section{LATAR BELAKANG}

Sebagai negara yang tergolong salah satu negara mega diversiti, Indonesia menyimpan banyak tumbuh-tumbuhan tropis yang berkhasiat obat dan telah lama digunakan oleh masyarakat dalam pengobatan tradisional. Cassia alata atau dikenal dengan nama Ketepeng Cina tersebar secara merata di hutan-hutan tropis Indonesia. Di beberapa daerah tumbuhan ini mempunyai nama lokal 
seperti Gelinggang oleh suku Banjar di Kalimantan Selatan dan Gulingkang oleh suku bugis di daerah Sulawesi Selatan.

Daun Cassia alata dapat mengobati Tinea pedis, merupakan salah satu penyakit dermatofita yang menyerang pada bagian kaki terutama pada bagian sela jari dan telapak kaki yang disebabkan oleh jamur Trichophyton rubrum (Anwar, 2015). Disamping itu, beberapa hasil penelitian menunjukkan ekstrak daun $C$. alata dapat berfungsi sebagai anti jamur seperti terhadap jamur $M$. furfur (Triana et al., 2016), Microsporum canis (Fajri et al., 2018), Trichophyton sp (Edo, 2017). Dalam penelitian ini dilakukan skrining fitokimia, toksisitas dan antioksidan terhadap ekstrak kasar daun gelinggang.

\section{METODE PENELITIAN}

\section{Bahan dan Peralatan}

Bahan yang digunakan dalam penenelitian ini adalah metanol, DPPH, telur udang Artemia salina, air laut, akuades, dan larutan DMSO. Adapun alat yang digunakan meliputi gelas ukur, gelas kimia, rotaevaporator, batang pengaduk, alat maserasi, mikropipet, mikroplat, wadah penumbuhan larva udang. Untuk uji antioksidan pengukuran absorbansi digunakan instrument UV-Vis Variant Cary 100/300.

\section{Prosedur Kerja}

\section{Ekstraksi daun Gelinggang}

Sampel berupa daun gelinggang terlebih dahulu dikeringan di udara terbuka, setelah kering daun tersebut dihaluskan. Sampel yang sudah dihaluskan (500 gram) kemudian dimaserasi ke dalam metanol selama tiga kali dua puluh empat jam. Filtrat yang diperoleh dari hasil penyaringan selanjutnya dipisahkan dengan pelarutnya pada suhu rendah menggunakan rotary evaporator.

\section{Uji fitokimia}

Uji fitokimia yang dilakukan meliputi uji alkaloid, triterpenoid, steroid, fenolik, flavonoid, kuinon, dan saponin yang mengacu pada prosedur penelitian sebelumnya (Erwin et al., 2015; Harborne, 1987).

\section{Uji bioassay}

Uji toksisitas terhadap ekstrak kasar yang dilakukan dengan metode brine shrimp letalithy test mengunggunakan larva udang Artemia salina. Adapun prosedur uji BSLT dilakukan sesuai dengan prosedur penelitian sebelumnya (Erwin et al., 2019; Karolina et al., 2018; Meyer et al., 1982). Untuk uji antioksidan dilakukan dengan metode peredanaman radikal DPPH sesuai adapun prosedur pengujian juga dilakukan sesuai dalam literatur (Bohari et al., 2019; Erwin, 2015).

\section{HASIL DAN PEMBAHASAN}

Hasil ekstraksi dengan cara maserasi terhadap daun gelinggang diperoleh ekstrak kasar kental berwarna coklat tua sebanyak 9 gram.

\section{Hasil Uji Fitokimia}

Hasil uji fitokimia menunjukkan bahwa ekstrak kasar daun gelinggang mengandung senyawa metabolit sekunder dari golongan alkaloid, triterpenoid, steroid, dan saponin (Tabel 1).

\section{Hasil Uji Toksisitas}

Hasil uji toksisitas dengan metode Brine Shrimp Lethality Test (BSLT) terhadap larva udang Artemia salina dapat dilihat dalam Tabel 2 dan Gambar 1. 
Tabel 1. Kandungan metabolit sekunder ekstrak daun Cassia alata L.

\begin{tabular}{|c|c|c|c|}
\hline No & Metabolit Sekunder & Gambar & Hasil \\
\hline 1. & Alkaloid & $(+)$ \\
\hline $\mathbf{2 .}$ & Triterpenoid & & $(+)$ \\
\hline $\mathbf{3 .}$ & Steroid & & $(+)$ \\
\hline $\mathbf{4 .}$ & Fenolik & & $(-)$ \\
\hline $\mathbf{5 .}$ & Flavonoid & & $(-)$ \\
\hline $\mathbf{6 .}$ & Kuinon & & $(+)$ \\
\hline $\mathbf{7 .}$ & Saponin & & $(-)$ \\
\hline
\end{tabular}

Keterangan:(+)mengandung metabolit sekunder

(-) tidak mengandung metabolit sekunder

Tabel 2. Hubungan antara konsentrasi dan nilai probit ekstrak daun Cassia alata L.

\begin{tabular}{cccccc}
\hline $\begin{array}{c}\text { Konsentrasi } \\
(\mathrm{ppm})\end{array}$ & $\begin{array}{c}\text { Log }_{10} \\
\text { Konsentrasi }\end{array}$ & $\begin{array}{c}\text { Total } \\
\text { Larva }\end{array}$ & $\begin{array}{c}\text { Jumlah Larva } \\
\text { Mati }\end{array}$ & \% Mortalitas & $\begin{array}{c}\text { Nilai } \\
\text { Probit }\end{array}$ \\
\hline 1000 & 3 & 10 & 9,3 & 93 & 6,48 \\
500 & 2,6989 & 10 & 7,6 & 76 & 5,71 \\
250 & 2,3979 & 10 & 6,3 & 63 & 5,33 \\
125 & 2,0969 & 10 & 3 & 30 & 4,48 \\
62,5 & 1,7959 & 10 & 5 & 50 & 5,00 \\
31,25 & 1,4948 & 10 & 5,3 & 53 & 5,08 \\
15,625 & 1,1938 & 10 & 4 & 40 & 4,75 \\
7,8125 & 0,8928 & 10 & 6 & 60 & 5,25 \\
\hline
\end{tabular}

Grafik hubungan antara nilai probit versus

log konsentrasi menghasilkan persamaan regresi linear, yaitu $y=0,5394 x+4,2101$. Persamaan regresi linier tersebut digunakan untuk menghitung nilai $\mathrm{LC}_{50}$, dengan rincian sebagi berikut:

$$
\begin{aligned}
& y=a x+b \\
& 5=0,5394 x+4,2101 \\
& x=\frac{5-4,2101}{0,5394} \\
& x=1,46 \\
& 10^{(1,46)}=28,84,
\end{aligned}
$$

maka nilai $\mathrm{LC}_{50}$ adalah $28,84 \mathrm{ppm}$ 


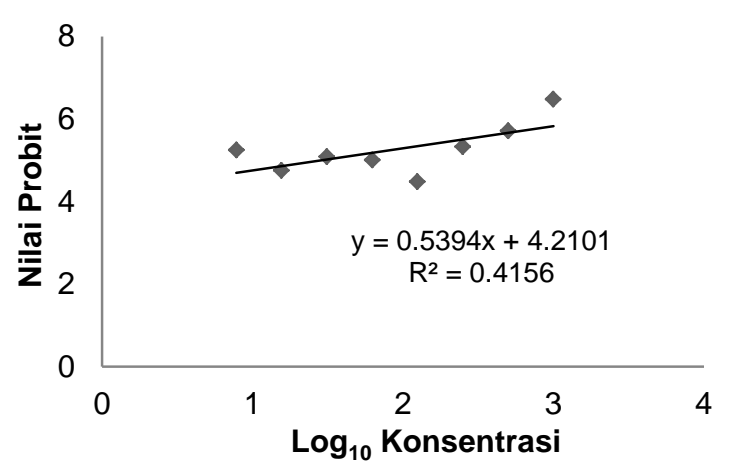

Gambar 1. Grafik regresi linier antara log konsentrasi dengan nilai probit ekstrak kasar daun Gelinggang

Menurut Meyer et al. (1982) nilai LC $_{50}$ di bawah $31 \mathrm{ppm}$ bersifat sangat toksik, sehingga ekstrak kasar Ketepeng Cina yang memiliki $L_{50} 28,84$ termasuk katagori sangat toksit. Ada korelasi positif antara sifat toksit terhadap larva udang $A$. salina dengan sifat sitotiksit. Sehingga sifat toksisitas eksrak kasar daun ketepeng ini dapat mengindikasikan adanya potensi sifat sitotoksit terhadap sel kanker.

\section{Aktivitas Antioksidan}

Hasil uji peredaman radikal DPPH ekstrak kasar daun gelinggang diperoleh aktivitas antioksidan ekstrak dan vitamin C sebagai pembanding (Tabel 2). Persamaan regresi linier antara konsentrasi dan $\%$ aktivitas antioksidan (\%AA) vitamin $\mathrm{C}$ adalah $\mathrm{y}=$ $8,0635 x+10,275, R^{2}=0,9965$ (Gambar 2).

Nilai $\quad \mathrm{IC}_{50}$ vitamin $\mathrm{C}$ diperoleh dari persamaan linear dengan rincian perhitungan:

$$
\begin{aligned}
& y=8,0635 x+10,275 \\
& 50=8,0635 x+10,275 \\
& x=\frac{50-10,275}{8,0635} \\
& x=4,92 \mathrm{ppm}
\end{aligned}
$$

Jadi besarnya nilai $\mathrm{IC}_{50}$ vitamin $\mathrm{C}$ adalah sebesar 4,92 ppm.

Tabel 2. Data absorbansi, \%AA, $\mathrm{IC}_{50}$ vitamin $\mathrm{C}$ dan ekstrak kasar daun Gelinggang

\begin{tabular}{ccccc}
\hline \multicolumn{2}{c}{$\begin{array}{c}\text { Konsentrasi } \\
(\mathrm{ppm})\end{array}$} & Absorbansi & $\begin{array}{c}\text { \% Aktivitas } \\
\text { Antioksidan (\%AA) }\end{array}$ & $\begin{array}{c}\mathrm{IC}_{50} \\
(\mathrm{ppm})\end{array}$ \\
\hline \multirow{4}{*}{ Vit. C } & 2 & 0,123 & 26,74 & \\
& 4 & 0,093 & 42,91 & 4,92 \\
& 6 & 0,072 & 56,88 & \\
Ekstrak & 8 & 0,042 & 75,84 & \\
kasar & 60 & 0,133 & 19,95 & \\
& 60 & 0,104 & 37,32 & 73,57 \\
& 80 & 0,079 & 52,69 & \\
\hline
\end{tabular}

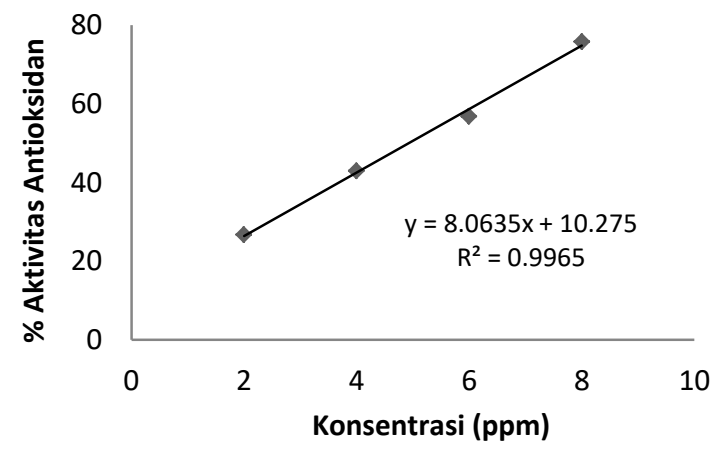

Gambar 2. Grafik hubungan konsentrasi dan $\%$ AA vitamin C.
Perhitungan $\mathrm{IC}_{50}$ ekstrak daun Gelinggang dilakukan berdasarkan persamaan regersi linier yang diperoleh antara konsentrasi dan \%AA ekstrak kasar daun gelinggang (Gambar 3), yaitu $y=0,7595 x+5,88 R^{2}=$ 0,9954, dimana $y=$ persentase aktivitas antioksidan (\%AA) dan $\mathrm{x}=$ konsentrasi ekstrak kasar daun gelinggang. 
$y=0,7595 x+5,88$

$50=0,7595 x+5,88$

$\mathrm{x}=\frac{50+5,88}{0,7595}$

$\mathrm{x}=73,57 \mathrm{ppm}$

Hasil perhitungan di atas menunjukan nilai $\mathrm{IC}_{50}$ ekstrak kasar daun Gelinggang adalah 73,57ppm.

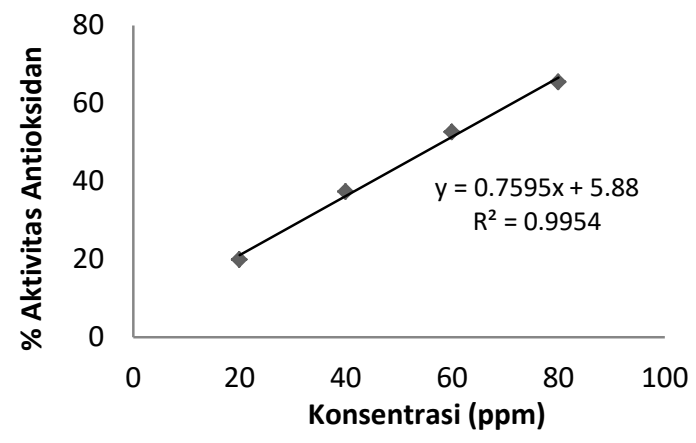

Gambar 3. Hubungan konsentrasi ekstrak kasar daun Gelinggang terhadap $\% A A$

Menurut Phongpaichit et al. (2007) pengujian antioksidan dengan peredaman radikal DPPH, jika nilai $\mathrm{IC}_{50}<10 \mathrm{mg} / \mathrm{mL}$ sangat aktif, $10-50 \mathrm{mg} / \mathrm{mL}$ aktif, $\quad 50-100$ $\mathrm{mg} / \mathrm{mL}$ moderat, $100-250 \mathrm{mg} / \mathrm{mL}$ lemah, dan $>250 \mathrm{mg} / \mathrm{mL}$ tidak aktif. Berdasarkan hal tersebut maka ekstrak kasar daun gelinggang termasuk memiliki sifat antioksidan yang moderat.

\section{KESIMPULAN}

Dari hasil penelitian tentang ekstrak kasar daun gelinggang, maka dapat disimpulkan bahwa ekstrak kasar daun gelinggang mengandung senyawa metabolit sekunder antara lain adalah alkaloid, triterpenoid, steroid, dan kuinon. Hasil uji toksisitas terhadap larva udang Artemia salina termsuk katagori sangat toksit sehingga berpotensi juga bersifat sitotoksit terhadap sel kanker. Hasil uji peredaman radikal bebas DPPH, ekstrak ini juga bersifat antioksidan yang moderat.

\section{UCAPAN TERIMA KASIH}

Penulis menyampaikan terima kasih kepada Kepala Laboratorium Anatomi dan Sistematika Tumbuhan Jurusan Biologi FMIPA UNMUL atas bantuannya telah mengindentifikasi tumbuhan ini. Dan juga kepada kepala Laboratorium Kimia Organik Jurusan Kimia FMIPA UNMUL yang telah menyediakan fasilitas laboratorium sehingga penelitian ini dapat diselesaikan sesuai dengan waktu yang direncanakan.

\section{DAFTAR PUSTAKA}

Anwar, A. N. D. (2015). Manfaat Daun Ketepeng Cina (Cassia alata L.) sebagai Antifungi pada Tinea Pedis. Jurnal Agromedicine, 2(4): 385-388.

Bohari, Karolina, A., Pratiwi, D. R., Erwin, \& Rahmadi, A. (2019). Toxicity Test, Antioxidant Activity Test and GC-MS Profile of The Active Fraction of Coptosapelta tomentosa (Blume) Root (Merung). Eurasian Journal of Biosciences, 13(2): 2403-2406.

Edo, T. (2017). Uji Daya Hambat Ekstrak Etanol Daun Ketepeng Cina (Cassia alata) Terhadap Pertumbuhan Jamur Trichophyton sp. Secara In Vitro. JURNAL ILMIAH MAHASISWA VETERINER, 1(1). https://doi.org/10.21157/jim vet..v1i1.2400

Erwin, E. (2015). Phytocemical Analysis and Anti-Oxidant Activity of The Wood Ethanolic Extracts of Sirih Hutan (Pipe aduncum). Jurnal Akta Kimia Indonesia (Indonesia Chimica Acta), 8(2): 52-59. https://doi.org/10.20956/ica.v8i2.2468

Erwin, E., Pusparohmana, W. R., Sari, I. P., Hairani, R., \& Usman, U. (2019). GC-MS Profiling and DPPH radical Scavenging Activity of The Bark of Tampoi (Baccaurea macrocarpa). 
F1000Research, $\quad 7(1977): \quad 1-8$. https://doi.org/10.12688/f1000research.16 643.2

Erwin, Sulistyaningsih, S., \& Kusuma, I. (2015). Isolation and MS Study of Friedelinol from The Leaves of Terap (Artocarpus odoratissimus Blanco). International Journal of Pharma and Bio Sciences, 6(1): 598-604.

Fajri, M., Marfu'ah, N., \& Artanti, L. O. (2018). Aktivitas Antifungi Daun Ketepeng Cina (Cassia alata L.) Fraksi Etanol, NHeksan, Dan Kloroform Terhadap Jamur Microsporium canis. Pharmaceutical Journal of Islamic Pharmacy, 2(1): 1-8. https://doi.org/10.21111/pharmasipha.v2i 1.2134

Harborne, J. (1987). Metode Fitokimia. Penerjemah: Padmawinata K, Soediro I. ITB, Bandung.

Karolina, A., Pratiwi, D. R., \& Akkas, E. (2018). Phytochemical and Toxicity Test of Merung Extracts (Coptosapelta tomentosa (Blume). JURNAL ATOMIK, 3(2): 79-82.

Meyer, B. N., Ferrigni, N. R., Putnam, J. E., Jacobsen, L. B., Nichols, D. E., \& McLaughlin, J. L. (1982). Brine Shrimp: A Convenient General Bioassay for Active Plant Constituents. Planta Medica, 45(5): 31-34. https://doi.org/10.1055/s-2007971236

Phongpaichit, S., Nikom, J., Rungjindamai, N., Sakayaroj, J., Hutadilok-Towatana, N., Rukachaisirikul, V., \& Kirtikara, K. (2007). Biological Activities of Extracts from Endophytic Fungi Isolated from Garcinia Plants. FEMS Immunology \& Medical Microbiology, 51(3): 517-525. https://doi.org/10.1111/j.1574695X.2007.00331.X

Triana, O., Prasetya, F., Kuncoro, H., \& Rijai, L. (2016). Aktivitas Antijamur Ekstrak Daun Ketepeng Cina (Cassia alata L.). Jurnal Sains dan Kesehatan, 1(6): 311315. https://doi.org/10.25026/jsk.v1i6.67 